\title{
THE EVALUATION OF THERMAL STRATIFICATION BY EXERGY
}

E. HAHNE, R. KÜBLER, J. KALLWEIT

Institut für Thermodynamik und Wärmetechnik, Univ. Stuttgart P. O. Box 801140 , D-7000 Stuttgart 80 , F.R.G.

\section{INTRODUCTION}

"What makes a good heat store?" This is a good question, difficult to answer.

is it a large store, with a large volume? And is the largest the best? We experienced this question when the first solar houses were built: many stores were oversized and never reached temperatures high enough for heating. It was learned that consumer needs, solar collector areas and storage capacity have to be well balanced to give a satisfying solar heating system. Not to speak of costs which usually promote the final decision.

A good store should be well insulated. But, of course, there are exceptions to this rule: a ground-store feeding a heat pump can use the surrounding earth for extra storage capacity; then insulation would be inhibitive.

A good store should allow for an efficient charging and discharging: so we need large heat exchangers. But every heat exchanger causes a temperature drop, i.e. an irreversibility or a degradation of heat. It would be best to get along without heat exchangers. But only for simple one-loop stores this is possible; for two loops with different fluids, e.g. water and antifreeze liquid, a heat exchanger is needed. Internal heat exchangers may cause convective flows inside the storage tank, so that water layers of different temperature become mixed. This unliked phenomenon is known as destruction of thermal stratification.

Thus, for a good store the aim must be:

- to fit into the system

- to have little external losses (energy losses to the surroundings)

- to have little internal losses (exergy losses due to mixing).

It is quite simple to calculate external losses; it is complicated and requires a number of assumptions to calculate internal degradation. But nevertheless, there is the need to quantify advantages and disadvantages of the various stores in order to compare them and to improve them.

2. TESTING OF DOMESTIC HOT WATER STORES

There exist test regulations for domestic hot water stores by the German DIN, the US ASHRAE and the CEC.

Such stores usually consist of a cylindrical tank with two ports for the domestic water and an internal heat exchanger. 


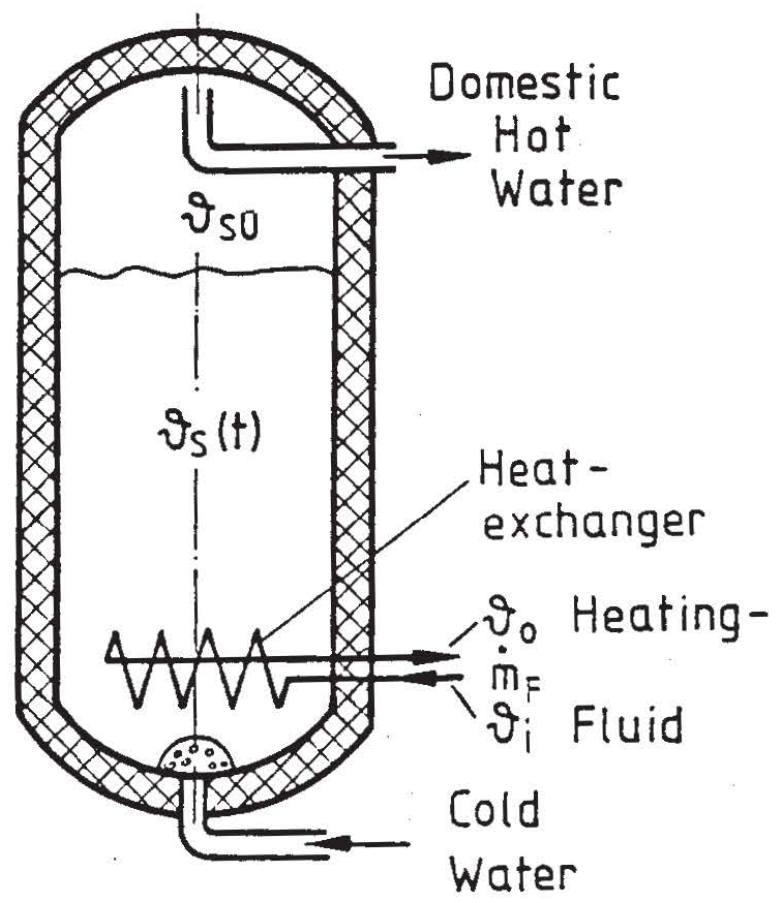

PIGURE 1. Domestic hot water store: Four-part water displacament store

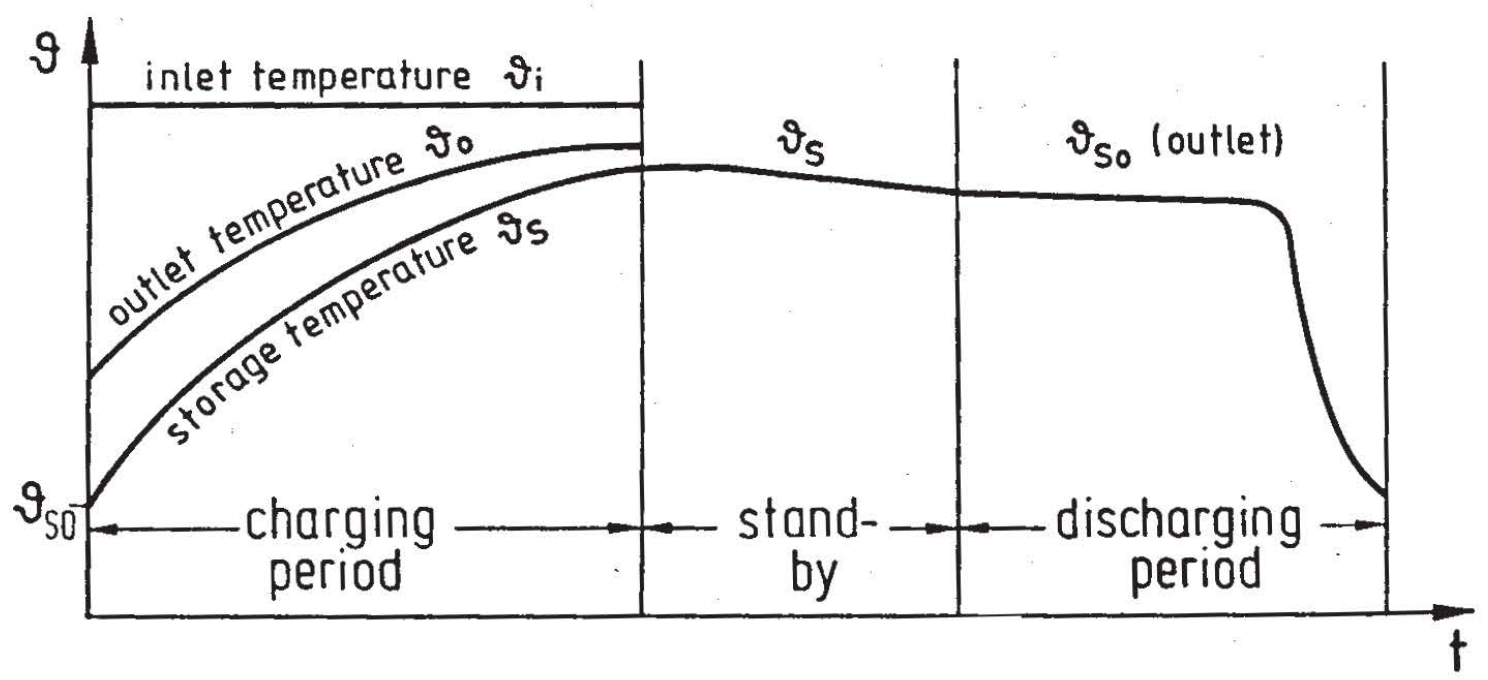

FIGURE 2. Temperature distribution vs. time for various modes of operation of a heat store

Such a store with four openings (ports) is shown in FIGURE 1. For charging, the heating fluid is circulated through the heat exchanger. For discharging, the stored hot water is displaced from the top of the tank by cold water which is fed into the bottom. These stores are operated in three different modes:

charging, standby and discharging.

The temperature distribution during the various modes of operation (when they follow each other consecutively) is shown in FIGURE 2. 
In order to evaluate the thermal insulation of a store, the so-called heat loss rate is determined. This is the product (UA) of the overall heat transfer coefficient of the store "U" and its heat loss area "A". It can be calculated from

$$
(U A)_{S a}=\frac{\dot{m}_{F} c_{p F}}{(3600 s)(25 K)} \sum_{t=0}^{3600 s}\left(\vartheta_{i}-\vartheta_{0}\right) \Delta t
$$

In order to evaluate this equation, a specified test procedure has to be followed: the mass flow rate of the heating water $\dot{m}_{F}$ shall be determined according to

$$
\dot{m}_{F}=\left(Q_{S} / \Delta \vartheta\right) /\left(c_{p F} t\right)
$$

with $Q_{S}$ as the theoretical storage capacity.

$$
\text { The ratio } Q_{S} / \Delta \vartheta=\sum_{j=1}^{n} m_{S_{j}} c_{S j}
$$

with $\mathrm{m}_{\mathrm{Sj}}$ representing all masses involved in storage, and $\mathrm{c}_{\mathrm{s}_{j}}$ their respective specific heat capacity. The time $t$ shaj be taken as four hours.

At the beginning of the test, the entire store shall be

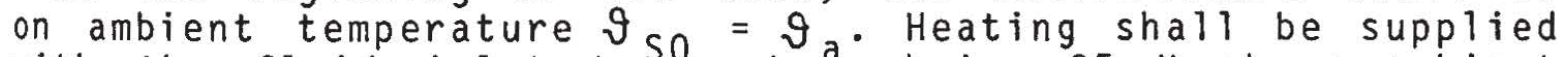
with the fluid inlet temperature being $25 \mathrm{~K}$ above ambient temperature $\left(\vartheta_{j}-\vartheta_{a}=25 \mathrm{~K}\right)$, until a uniform and stable temperature distribution (approximately $25 \mathrm{~K}$ above ambient) is reached within the store. An observable indication for this can be the more or less stable outlet temperature. After such a stable situation has been reached, the actual test is performed with the measurements of the temperature difference $\vartheta_{j}-\vartheta_{0}$ of the heating fluid for one hour. These measured data are inserted in equ. (1). This equ. (1) is obtained from the heat balance

$$
\begin{gathered}
Q_{\text {LoS } S}=Q_{\text {in }}-Q_{\text {out }} \\
(U A)_{S a}\left(\vartheta_{S}-\vartheta_{a}\right) \Delta t *=\dot{m}_{F} c_{p F}\left(\vartheta_{i}-\vartheta_{0}\right) \Delta t * \\
\text { with } \vartheta_{S}-\vartheta_{a}=25 \mathrm{k} \text { and } \Delta t *=3600 \mathrm{~s}
\end{gathered}
$$

For the evaluation of the heat exchanger a so-called charging efficiency can be defined.

Efficiencies are principally ratios of energies or powers giving figures between zero and one. They compare actually achievable values to maximum values which would be obtained under ideal conditions. 
For the charging efficiency can be defined:

$\eta_{c t_{f}}=\frac{\int_{0}^{t_{f}} \dot{m}_{F} c_{p F}\left(\vartheta_{i}-\vartheta_{0}\right) d t-\int_{0}^{t_{f}}(U A)_{S a}\left(\vartheta_{S}-\vartheta_{a}\right) d t}{\dot{m}_{F} c_{p F}\left(\vartheta_{i}-\vartheta_{S O}\right) t_{f}}$

The first integral represents the heat actually delivered to the store by the heating fluid, the second integral represents the heat losses from the store. The denominator gives the maximum heat which could be delivered if the temperature difference $\vartheta_{i}-\vartheta_{\text {so }}$ which existed at the beginning of charging would persist through the entire filling time $t_{F}$. By filling time we understand the period required by a mass flow $\dot{m}_{F}$ to deliver the same thermal capacity as the store contains:

$$
\sum m_{S i} c_{S i}=\dot{m}_{F} c_{p F} t_{f}
$$

or

$$
t_{f}=\frac{\sum m_{S i} c_{s i}}{\dot{m}_{F} c_{p F}} \approx \frac{m_{S} c_{p S}}{\dot{m}_{F} c_{p F}} \approx \frac{m_{S}}{\dot{m}_{F}}
$$

If only the stored water is considered and the specific heat capacities are assumed equal, the filling time is the time to replace completely the stored mass $m_{s}$ by the mass flow $\dot{m}_{F}$, e.g. in a piston-like flow through the store.

In order to calculate the charging efficiency, the storage temperature $\vartheta_{s}$ has to be measured or assumed and the question arises, what is the proper storage temperature for this purpose and what is the role of temperature in general?

\section{THE PRINCIPLE OF EXERGY}

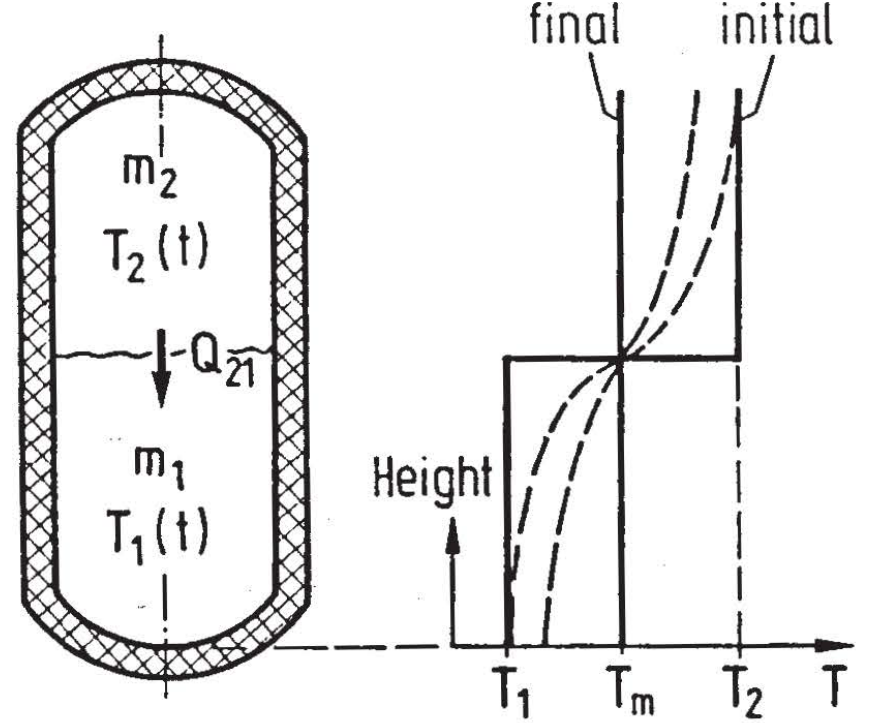

FIGURE 3 .

Temperature equalization within an adiabatic storage tank when $m_{1}=m_{2}$ 
There are also other definitions for efficiency. They have in common that they are based on energies and do not account for the value of energy at various temperatures. But in thermal stores we strive for layers with high temperatures, i.e. for a thermal stratification. We wish to obtain it, we wish to keep it; but with energy we have no property to rate it. A simple example shall demonstrate this:

we assume an ideally insulated storage tank. FIGURE 3, with the upper half filled with water of $40^{\circ} \mathrm{C}$ and the lower half with $20^{\circ} \mathrm{C}\left(\mathrm{m}_{1}=\mathrm{m}_{2}\right)$. If we wait until internal conduction has equalized all temperature differences, the stored water will have a final mean temperature of $30^{\circ} \mathrm{C}$. Neither heat nor work were delivered from the store, therefore - according to the first law - its energy remains the same, before and after the equalization. But is it still the same for our purpose? If we take a shower before equalization, we certainly appreciate $40^{\circ} \mathrm{C}$ more than the $30^{\circ} \mathrm{C}$ afterwards; and the fact that we can have twice as much lukewarm water, may scarcely compensate for the higher temperature.

For room heating purposes, the smaller temperature span to the surroundings may not suffice at all, or require additional equipment, e.g. larger heaters or heat pumps.

Thus, the value of the energy in the store has deteriorated by the equalization, although the energy remained the same.

A criterion for the quality of energy can be obtained when the second 1 aw is taken into account. It states - as a restriction to the first law - heat cannot be fully converted into work, or, high-temperature heat can naturally satisfy all requirements of low-temperature heat, but not vice versa. Work, on the other hand, can be fully converted into heat. The fact that energy cannot always be fully converted into any other energy has led to a subdivision of the concept of energy:

Energy is composed of a part which can be converted

into any other energy and a part which cannot.

The part which can be converted is named "exergy" or "availability" (in English literature). The non-convertible part part is called "anergy" (which might be better spelled "unergy" in English). Thus, it can be stated

$$
\begin{aligned}
\text { Energy } & =\text { Exergy }+ \text { Unergy } \\
E & =E_{X}+B_{X}
\end{aligned}
$$

Both exergy and unergy may be zero.

Heat energy is exergy plus unergy. Exergy is that part which can be converted into work. At high temperature more heat can be converted than at low temperature and at ambient temperature heat cannot be converted at all. Thus, the exergy of heat deteriorates, when its temperature approaches ambient temperatures. This corresponds exactly with our needs for a value of energy. How can exergy be quantified?

According to a Carnot-Process between a constant temperature $T$ and the ambient temperature $T_{a}$, the maximum work obtained from heat is: 


$$
W_{\text {max }}=E_{x}=\frac{T-T_{a}}{T} Q=Q-\frac{T_{a}}{T} Q
$$

The maximum work is the exergy; the unergy is

$$
B_{x}=\frac{T a}{T} Q
$$

Changes of exergy depend on changes of energy (heat) according to

With

$$
d E_{X}=d Q-\frac{T_{a}}{T} d Q
$$

$$
d Q=m_{S} \cdot c_{p S} d T
$$

we obtain from equ. (12) the exergy of heat at a temperature $T$

$$
E_{x}=\int_{T_{a}}^{T} m_{S} c_{p S}\left(1-\frac{T_{a}}{T}\right) d T
$$

which is valid also for non-isothermal processes. From equ. (14) we obtain the exergy of a hot water store at temperature $T_{1}$

$$
E_{x S}\left(T_{l}\right)=m_{S} c_{p S}\left[\left(T_{1}-T_{a}\right)-T_{a} \ln \frac{T_{1}}{T_{a}}\right]
$$

If the store is heated to a temperature $T_{2}$, the exergy increase

$$
\begin{aligned}
\Delta E_{X}= & E_{x}\left(T_{2}\right)-E_{x}\left(T_{1}\right) \text { is } \\
& \Delta E_{X S}=m_{S} c_{p S}\left[\left(T_{2}-T_{1}\right)-T_{a} \ln \frac{T_{2}}{T_{1}}\right]
\end{aligned}
$$

From equ. (16) it can be seen that the exergy increase is not linear with $\left(T_{2}-T_{1}\right)$ as for energy (first term on the right hand side). It depends on the temperature level and the ambient temperature. At a high temperature level the ratio $T_{2} / T_{1}$ is smaller than at a low level (provided the difference $T_{2}^{2}-T_{1}$ is the same). Of course, when the ambient temperature - which is the lowest possible temperature in the process - is high, the unergy is large and exergy is small.

The relative energy difference $\Delta E_{x} / m c$ is plotted in FIGURE4 versus the temperature difference $T^{X}-T_{1}$. Also the relative energy difference $\Delta Q / m c$ is plotted ${ }^{2}$ in this figure. The energy increases linearly, the exergy increases progressively with increasing temperature $T_{2}$. Thus, the same addition of energy is more valuable - yields a higher exergy - at high temperatures than at low. On the other hand, an energy loss, at high temperature is much more serious than at low. It can also be seen that exergy increases with the temperature level. 


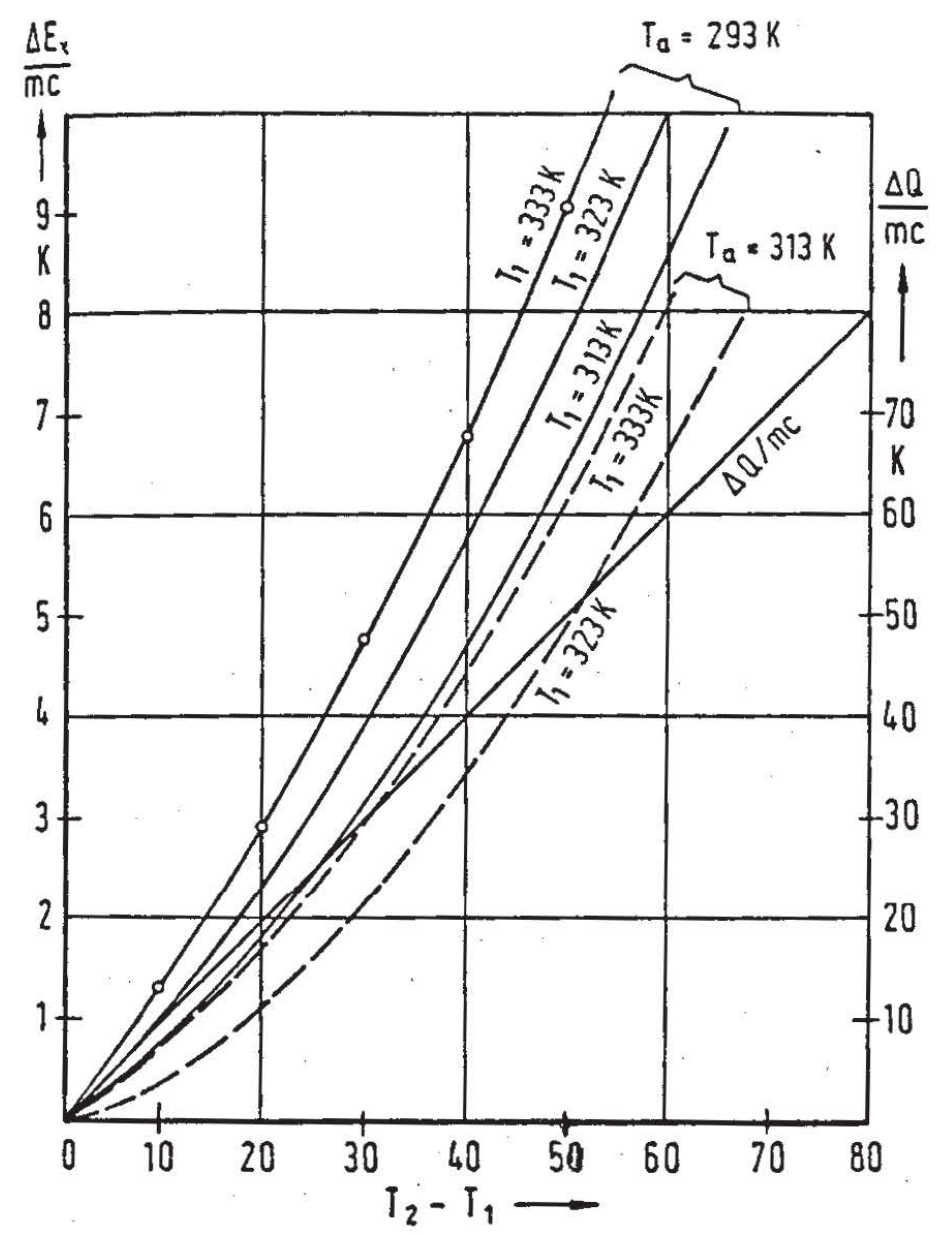

FIGURE 4. Relative exergy- and energy growth for various starting temperatures $T_{1}$ and ambient temperatures $T_{a}$

In light of this, the deterioration of the energy value for the example of FIGURE 3 shall be quantified:

The energy balance is

$$
Q_{2 \rightarrow m}=Q_{m}-1
$$

The exergy balance is

$$
\left(E_{x 2}+E_{x 1}\right)-E_{x m}=\Delta E_{x}
$$

or with $m_{1}+m_{2}=m_{S}$

$$
\Delta E_{x}=m_{S} c_{p S} T_{a}\left(\frac{m_{1}}{m_{S}} \ln \frac{T_{m}}{T_{1}}-\frac{m_{2}}{m_{S}} \ln \frac{T_{2}}{T_{m}}\right)
$$
With temperatures $T_{1}=T_{a}=293 \mathrm{~K}, T_{2}=313 \mathrm{~K}$ and $T_{m}=303 \mathrm{~K}$
and $m_{1}=m_{2}$ we obtaln an exergy ${ }_{\text {loss }}{ }^{2}$ of

$$
\Delta E_{X}=m_{s} \cdot 0,668 \mathrm{~kJ}
$$


Which is about half of the entire exergy originally contained in the store

$$
E_{x 2}=\left(0.5 \cdot m_{S}\right) \cdot 2.734 \mathrm{~kJ} \text {. }
$$

Thus, the quantitative result of the example is: by temperature equalization within the store, the energy does not change the exergy, however, drops to about $50 \%$. This means that the capability to yield work has dropped to half.

\section{EXERGETIC EVALUATIONS}

Any thermal store experiences these three different modes of operation:

- charging, when the store is heated by some outside heat source

- standby, when purposely no heat is added or withdrawn. There might be heat losses due to internal conduction and convection or to the ambient

- discharging when heat is withdrawn from the store to supply some outside consumer.

often these modes do not follow each other consecutively, but both charging and discharging occur intermittently or combined. Thus, all processes depend heavily on time. In order to have clear conditions it is assumed here that the three modes do follow each other consecutively for certain periods.

The evaluations will be performed for a so-called "fully mixed store", i.e. a store of uniform temperature and with uniform temperature changes for any energy input or output. A fully mixed store contains the minimum exergy; if there is more exergy found in a real store, this.means it is stratified.

The store shall be a 4-port water displacement store as shown in FIGURE 1. Charging is started at the uniform initial store temperature $\vartheta_{S O}$ by passing a heat fluid $\dot{m}_{F}$ with a constant inlet temperature $\vartheta_{j}$ through the heat exchanger. The instantaneous heat exchanger efficiency is

$$
\varepsilon=1-\exp \left[-\frac{(U A)}{\dot{m}_{F} c_{p}}\right]=1-\frac{\vartheta_{0}-\vartheta_{S}}{\vartheta_{i}-\vartheta_{S}}
$$

This allows for the calculation of the fluid outlet temperature $\vartheta_{0}$ provided the storage temperature $\vartheta_{S}$ is known.

From a heat balance of the store, the differential equation for the transient temperature change can be obtained

$$
\frac{d \theta_{S}}{d t}=c \theta_{S}+B
$$

with

$$
\theta_{S}=\vartheta_{S}-\vartheta_{a}
$$




$$
c=\frac{(U A)_{S a}+\dot{m}_{F} c_{p} \varepsilon}{m_{S} c_{p S}} ; \quad B=\frac{\dot{m}_{F} c_{p} \varepsilon}{m_{S} c_{p S}}\left(\vartheta_{i}-\vartheta_{a}\right) \quad(22 a, 22 b)
$$

and the solution for the store temperature is:

$$
\vartheta_{S}(t)=\vartheta_{a}+\frac{B}{C}+\left[\vartheta_{S O}-\vartheta_{a}-\frac{B}{C}\right] \exp (-C t)
$$

From this solution the fluid outlet temperature $\vartheta_{0}$ can be obtained as:

$$
\begin{aligned}
& \vartheta_{0}(t)=\left[\vartheta_{i}-\frac{B}{c}-\left(\vartheta_{S O}-\vartheta_{a}-\frac{B}{c}\right) \exp (-c t)-\vartheta_{a}\right] . \\
& \cdot \exp \left(-\frac{(U A)}{\dot{m}_{F} c_{p}}\right)+\frac{B}{c}+\left(\vartheta_{S O}-\vartheta_{a}-\frac{B}{c}\right) \exp (-c t)+\vartheta_{a}
\end{aligned}
$$

It should be noted that the overall heat transfer coefficient $U$ for both the heat exchanger rate (UA) and the storage loss rate (UA) depends on the storage temperature. For calculations overa larger period, proper subdivisions for time and respective (UA) can be made.

For flow processes, an exergy flow corresponds to a heat flow. Thus, the exergy flow of the incoming heat flow during charging is

$$
\dot{E}_{x}^{c}\left(T_{i}\right)=\dot{m}_{F} c_{p}\left[\left(T_{i}-T_{a}\right)-T_{a} \frac{T_{j}}{T_{a}}\right]
$$

The exergy flow of the outgoing heat flow is correspondingly

$$
\dot{E}_{x}^{c}\left(T_{0}(t)\right)=\dot{m}_{F}^{c} c_{p}\left[\left(T_{0}(t)-T_{a}\right)-T_{a} \ln \frac{T_{0}(t)}{T_{a}}\right]
$$

The fluid outlet temperature $T_{0}$ can be obtained from equ. (24). From the exergy of the store, equ. (15), we obtain its exergy flow, i.e. the net flow into the storage medium, at temperature $T_{S}(t)$ :

$$
\dot{E}_{x}^{c}\left(T_{S}(t)\right)=\frac{d}{d t} m_{S} c_{p S}\left[\left(T_{S}(t)-T_{a}\right)-T_{a} \ln \frac{T_{S}(t)}{T_{a}}\right]
$$

With $T_{S}(t)$ from equ. (23) this net exergy flow is

$$
\begin{aligned}
\dot{E}_{x}^{C}\left(T_{S}(t)\right) & =m_{S} C_{p S}\left(B-C\left(T_{S O}-T_{a}\right)\right) \exp (-C t)- \\
& -\frac{T_{a}\left(B-C\left(T_{S O}-T_{a}\right)\right) \exp (-C t)}{\frac{B}{C}-\left(\frac{B}{C}-\left(T_{S O}-T_{a}\right) \exp (-C t)-T_{a}\right.}
\end{aligned}
$$


The net flow is less than the exergy flow delivered from the heat exchanger, because the latter also includes the external losses. In order to rate stores, a ratio of exergies is introduced similar to the energetic efficiency; this is called exergetic efficiency:

$$
\zeta=\frac{E_{x \text { actual }}}{E_{x \text { maximum }}}
$$

\section{THE EXERGETIC EFFICIENCY FOR CHARGING}

We consider the following model: The maximum exergy is fed into the store in a piston-like flow with the heating fluid at constant inlet temperature pushing out the cold fluid. No mixing shall occur. Thus, we obtain a perfect stratification with a moving boundary. The store is completely charged after the filling time $t_{f}$.

But, actually, the heat is fed into the store by way of a heat exchanger and the store is supposed to be fully mixed. The following definition of the exergetic charging efficiency provides minimum values:

$$
\zeta_{c t f}=\frac{\int_{0}^{t_{f}} \dot{E}_{x}^{c}\left(T_{S}(t)\right) d t}{\int_{0}^{t_{f}} \dot{E}_{x}^{c}\left(T_{i}\right) d t-\int_{0}^{t_{f}} \dot{E}_{x}^{c}\left(T_{S 0}\right) d t}
$$

If there is, however, in reality a piston-like flow with no mixture (ideal 2-port store) we can obtain $\zeta_{\text {tf }}=1$.

The net exergy of the numerator lequ.30 tf $^{\mathrm{c} a n}$ be obtained from equ.(28) as:

$$
\begin{gathered}
\int_{0}^{t} \dot{E}_{x}^{C}\left(T_{S}(t) d t=m_{S} C_{p S}\left[\left(1-\exp \left(-C t_{f}\right)\right)\left(\frac{B}{C}-\left(T_{S O}-T_{a}\right)\right)-\right.\right. \\
\left.-T_{a} \ln \frac{\frac{B}{C}+T_{a}-\left[\frac{B}{C}-\left(T_{S O}-T_{a}\right) \exp \left(-C t_{f}\right)\right]}{T_{S O}}\right]
\end{gathered}
$$

and the maximum exergy of the denominator using equ.(25) as:

$\int_{0}^{t_{f}} \dot{E}_{x}^{c}\left(T_{i}\right) d t-\int_{0}^{t_{f}} \dot{E}_{x 0}\left(T_{S O}\right) d t=\dot{m}_{F} c_{p} t_{f}\left[T_{i}-T_{S O}-T_{a} \ln \frac{T_{I}}{T_{S O}}\right]^{(32)}$

For comparison, also the energetic charging efficiency, equ. (6) is used.

For zero heat losses, the solution of equ. (30) is for an arbitrary time 


$$
\zeta_{c}=\frac{\varepsilon(1-\exp (-C t))\left(T_{i}-T_{S O}\right)-T_{a} \ln \frac{T_{i}-\left(T_{i}-T_{S O}\right) \exp (-C t)}{T_{S O}}}{t_{f}\left(T_{i}-T_{S O}-T_{a} \ln T_{i} / T_{S O}\right)}
$$

and of equ. (6)

$$
\eta_{c}=\varepsilon \frac{1-e^{-c t}}{c t}
$$

For an ideal heat exchanger with (UA) $\rightarrow \infty$, $\varepsilon$ becomes 1 .

Results of these equations for $\varepsilon=1$ are shown in FIGURE 5 .

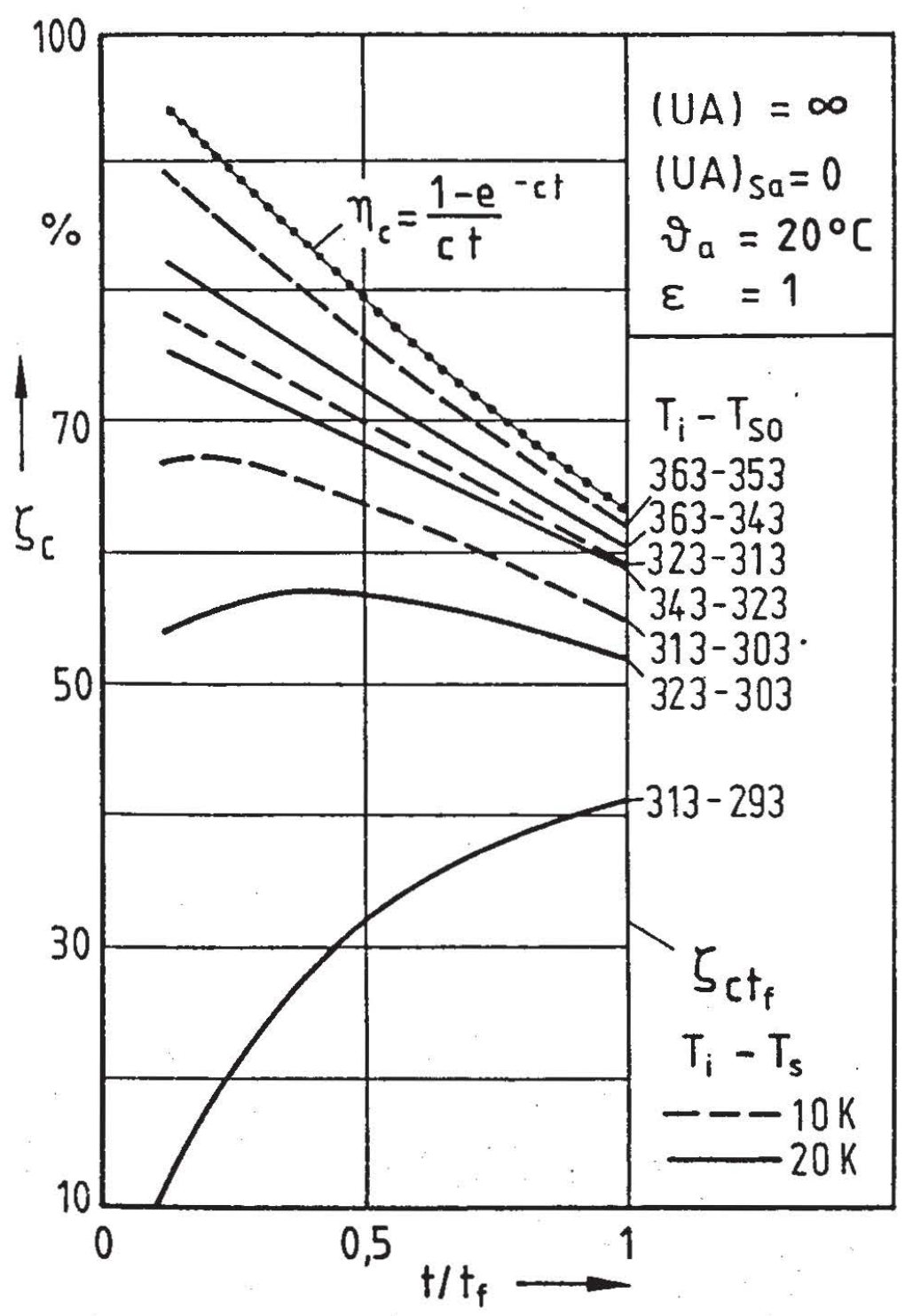

FIGURE 5. Exergetic charging efficiency and energetic efficiency in its dependence on time 
The efficiency is presented versus a reduced filling time $t / t_{f}$ in order to show how necessary it is to agree on a certain time, when efficiencies are discussed. Here the filling time is used as characteristic and all further comparison is based on $t / t_{f}=1$ :

In FIGURE 6, the increase in charging efficiency is shown, when the inlet temperature of the heating fluid is increased. When the initial temperature span $T_{j}-T_{s}$ is smaller, the efficiency is higher. For perfect heat exchangers, $\varepsilon=1$, this plot is valid for all ratios of $\mathrm{m}_{\mathrm{S}} / \dot{\mathrm{m}}_{\mathrm{F}}$.

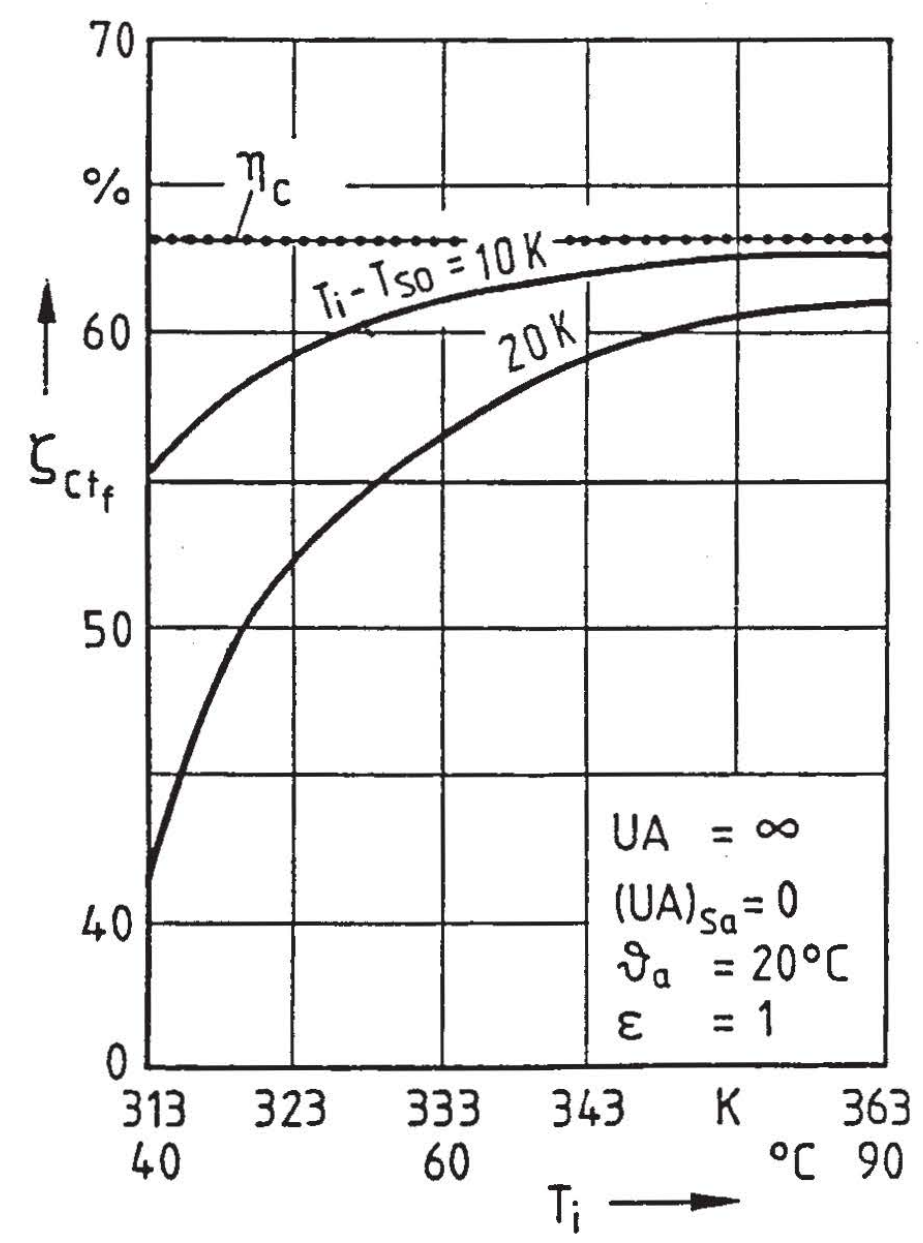

FIGURE 6. Exergetic charging efficiency and energetic efficiency dependent on charging inlet temperature

For the perfect heat exchanger and an ideally insulated store, the energetic efficiency is completely invariant to temperatures. According to equ. (34) this also holds for nonperfect heat exchangers as long as (UA) $\mathrm{Sa}=0$ (equ. (22a)). Thus, the energetic efficiency cannot help when the best temperature conditions for charging are discussed.

For non-perfect heat exchangers and stores with heat losses, the exergetic efficiencies are shown in FIGURES 7 and 8 . For comparison again the energetic efficiency is presented. With a larger heat transfer area $A$ or a better overall heat transfer coefficient $U$, the efficiency increases. Even for high 


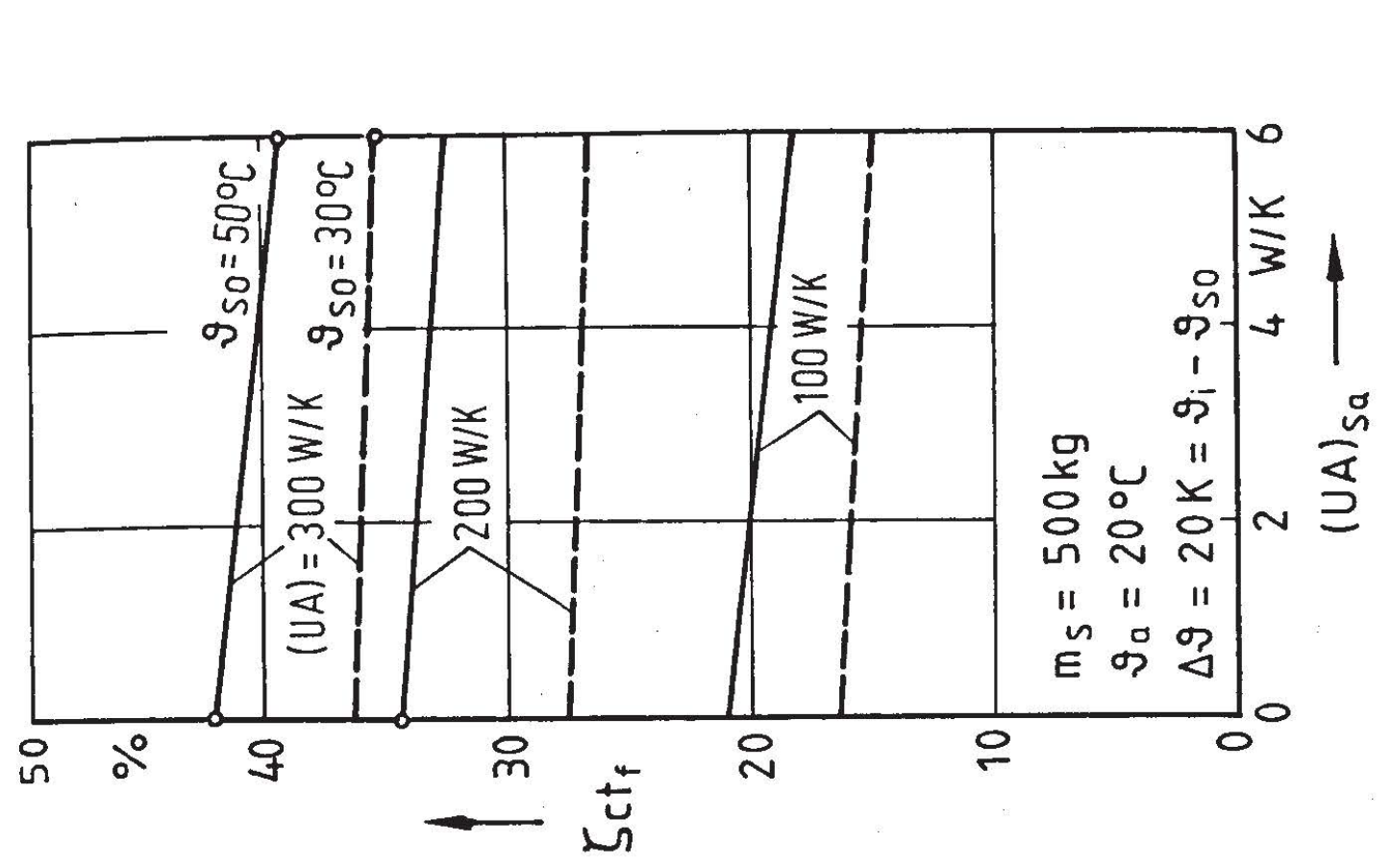

U

엉

$+$

บ

-

4 的

a) 0

品

бू

$\frac{1}{\sigma}$

능

$\therefore+$

$+4$

들

(1)

$\times$ 임

山

$\infty$

崩

芒

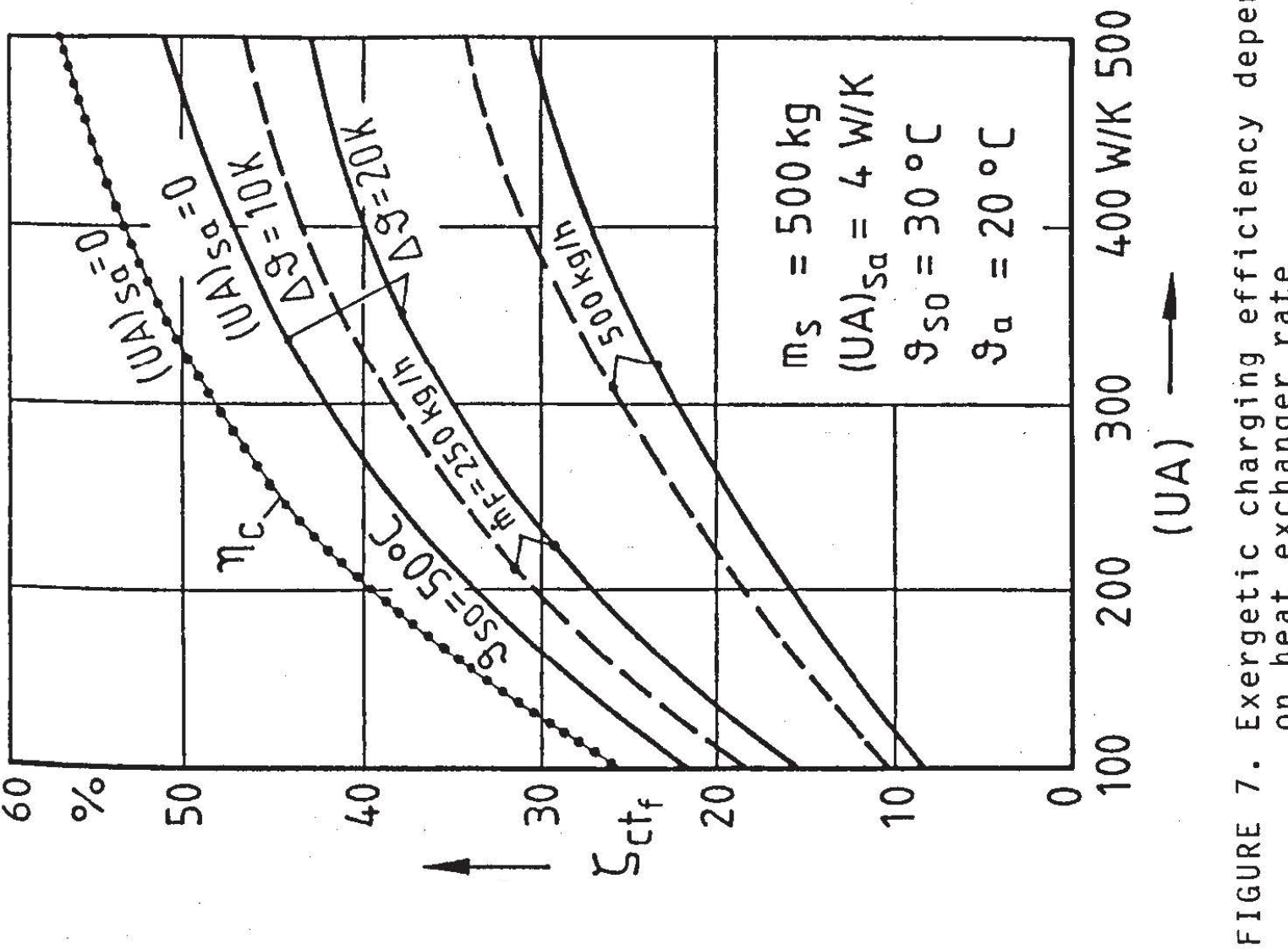


heat exchanger rates, the efficiency increase $\Delta \zeta \Delta(U A)$ is still considerable, e.g. $4 \% / 100 \mathrm{~W} / \mathrm{K}$, so that improvements still appear advantageous.

on the other hand, improvements in insulation do not appear pressing for the charging period which is here 2 hours. FIGURE 8 gives a decrease in exergetic efficiency of $0.2 \%$ when the heat loss rate increases by $1 \mathrm{~W} / \mathrm{k}$. Of course, this will be different with long charging- or standby periods.

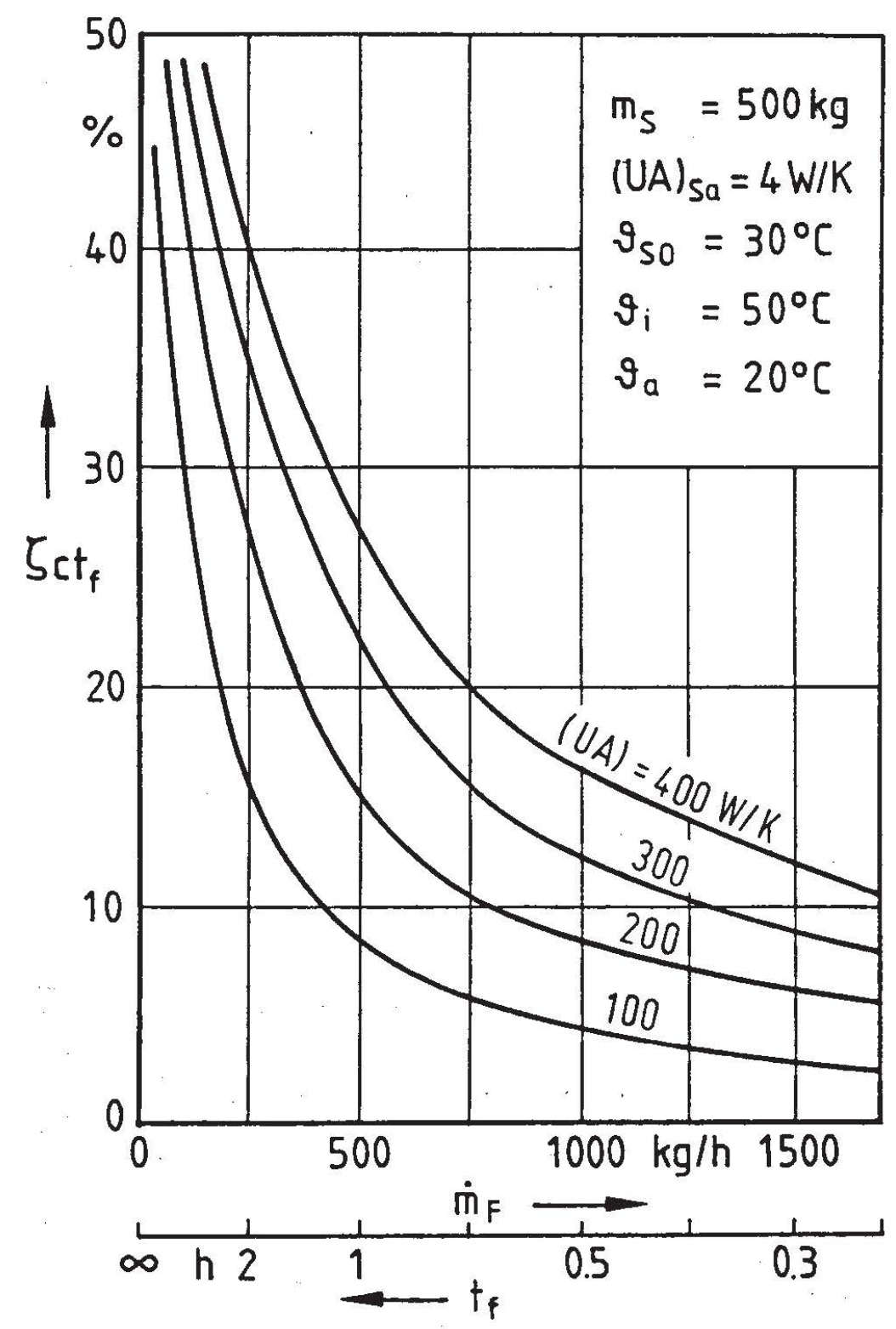

FIGURE 9. Exergetic charging efficiency dependent on the mass flow rate for various heat exchanger rates

The effect of mass flow rate is shown in FIGURE 9. The flowrate $\dot{m}_{\text {f }}$ and the filling time are inversely proportional; if the store would be charged with an almost zero flowrate, the charging time would be infinitely long. Thermodynamically this is an advantageous situation, as all storable energy 
is stored; correspondingly, ail curves in FIGURE 9 are orientated towards the $100 \%$ mark for this case (of course, there remain exergetic losses due to finite temperature heat trans ferl. On the other hand, with large fluid flow rates, most of the energy passes un-utilized through the heat exchanger. For a heat exchanger of poor quality, i.e. low UA, the exergetic efficiency is low. It does not help to charge a poor heat exchanger with a large flow rate in order to compensate its deficiencies. On the contrary, it would be better to use a small flowrate for poor heat exchangers and put up with long charging times.

The effect of the temperature level in the store is illustrated in FIGURE 10. Up to $10 \mathrm{~K}$ above the ambient temperature, there is a steep increase in the exergetic efficiency; at higher storage temperatures, $\zeta$ temains about constant. The effect of the initial temperature difference $\Delta \vartheta=\vartheta_{j}-\vartheta_{S}$ is presented in FIGURE 11. Only at high initial storage temperatures $\left(50^{\circ} \mathrm{C}\right)$, the temperature difference $\vartheta_{i}-\vartheta_{\text {So }}$ exhibits little effects upon the efficiency.

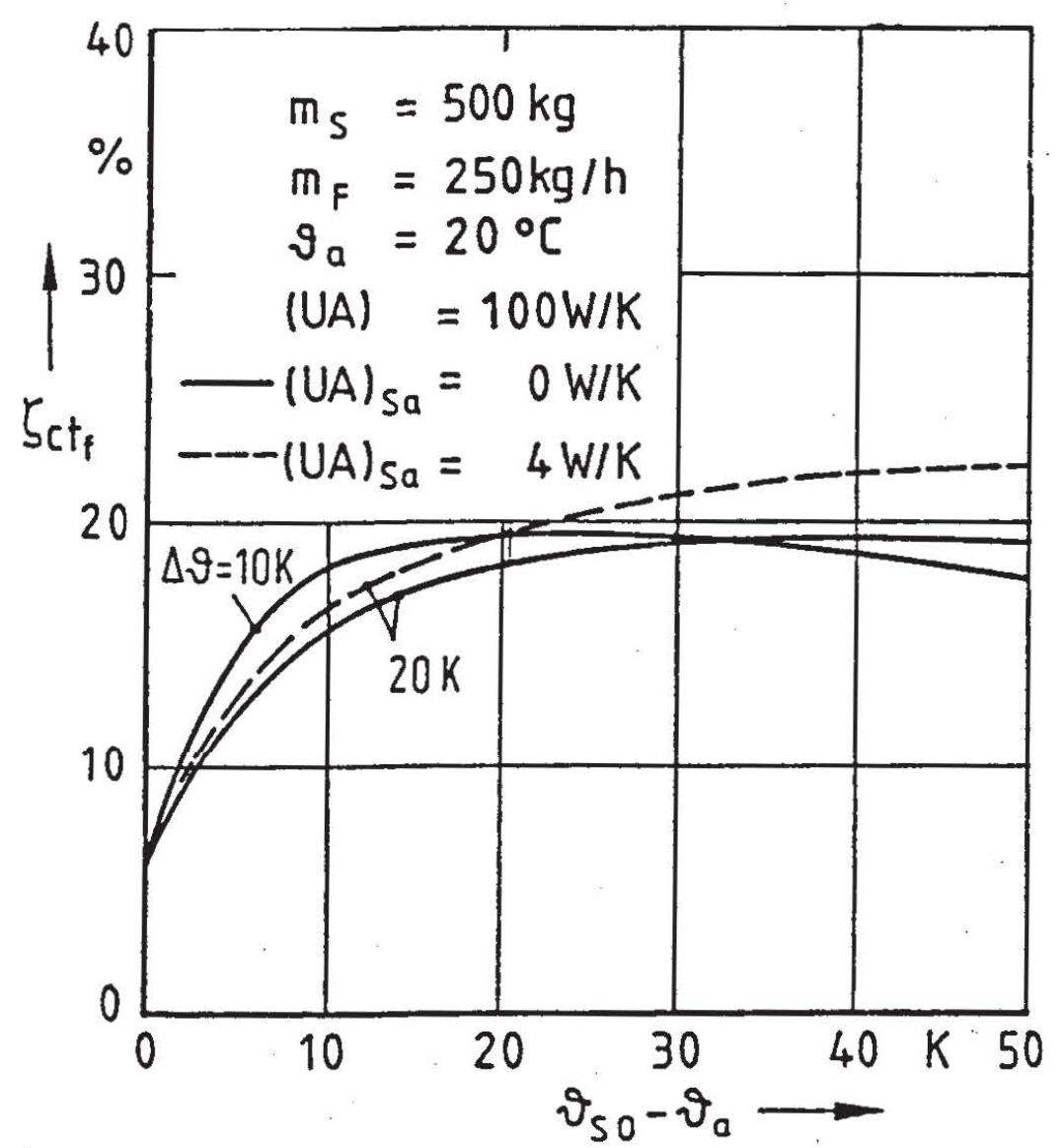

FIGURE 10. Exergetic charging efficiency dependent on the initial storage temperature

Summarizing: for a large exergetic charge efficiency, we need a good heat exchanger rate (UA $=400 \mathrm{~W} / \mathrm{K}$ ), an initia) store temperature about. $30 \mathrm{~K}$ above ambient and a filling time of 2 hours or more. The effects of other parameters are secondary. 


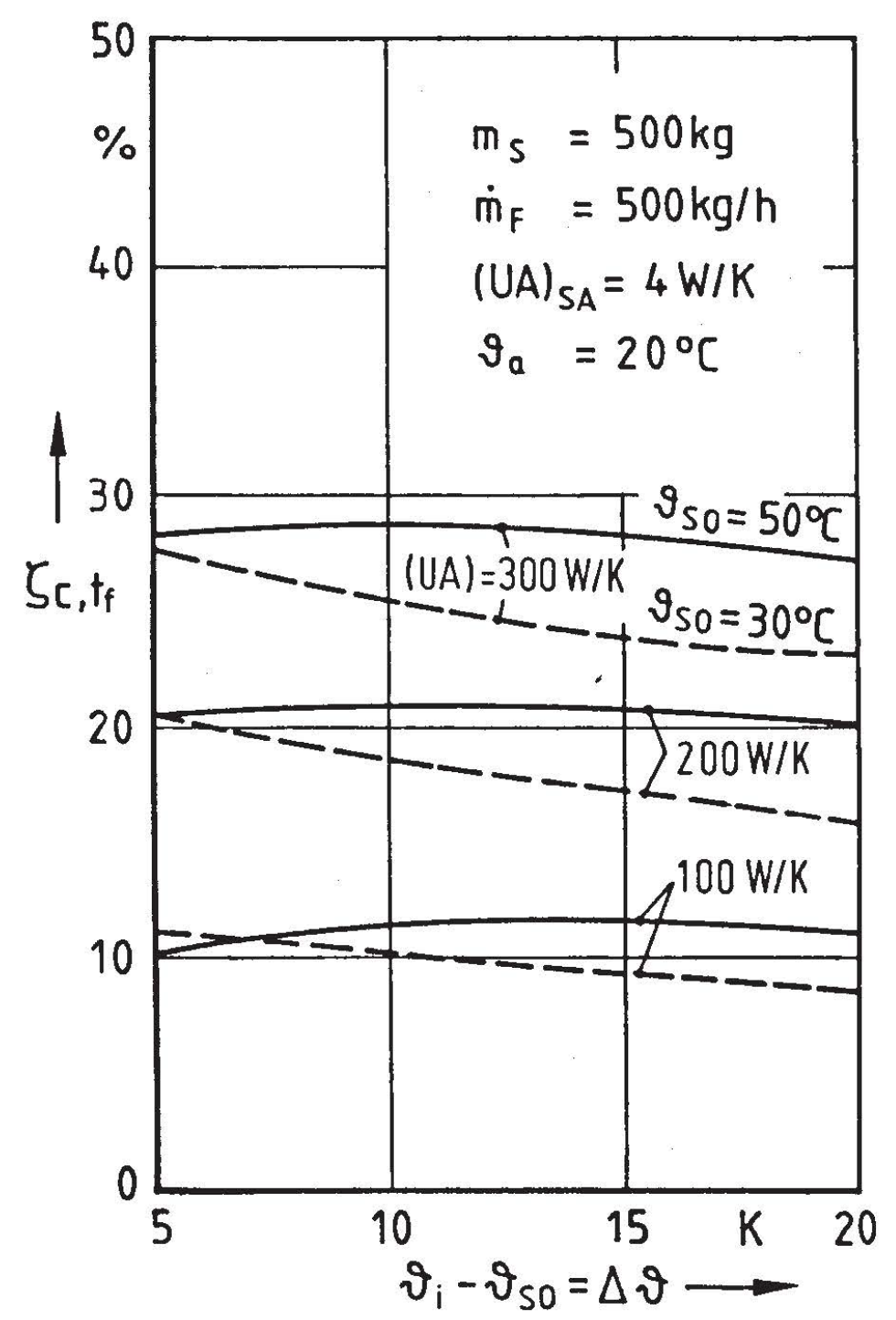

FIGURE 11. Exergetic charging efficiency dependent on initial temperature difference

\section{THE EXERGETIC EFFICIENCY DURING STANDBY}

Between charging and discharging, there may be periods when the store is not used. In most stores a thermal stratification will then form due to external losses and internal convection. We have considered a fully mixed store for charging and we remain with this concept for standby. As an exergetic efficiency we define the ratio of the exergy in the fully mixed store at a certain time, to the exergy originally in the store when the charging period ended; i.e. the standby period started at $t_{f}$ and temperature $\vartheta_{S t_{f}}$

$$
\zeta_{S b}(t)=\frac{E_{x S}^{S b}(T(t))}{E_{X S}^{c}\left(T_{t f}\right)}
$$




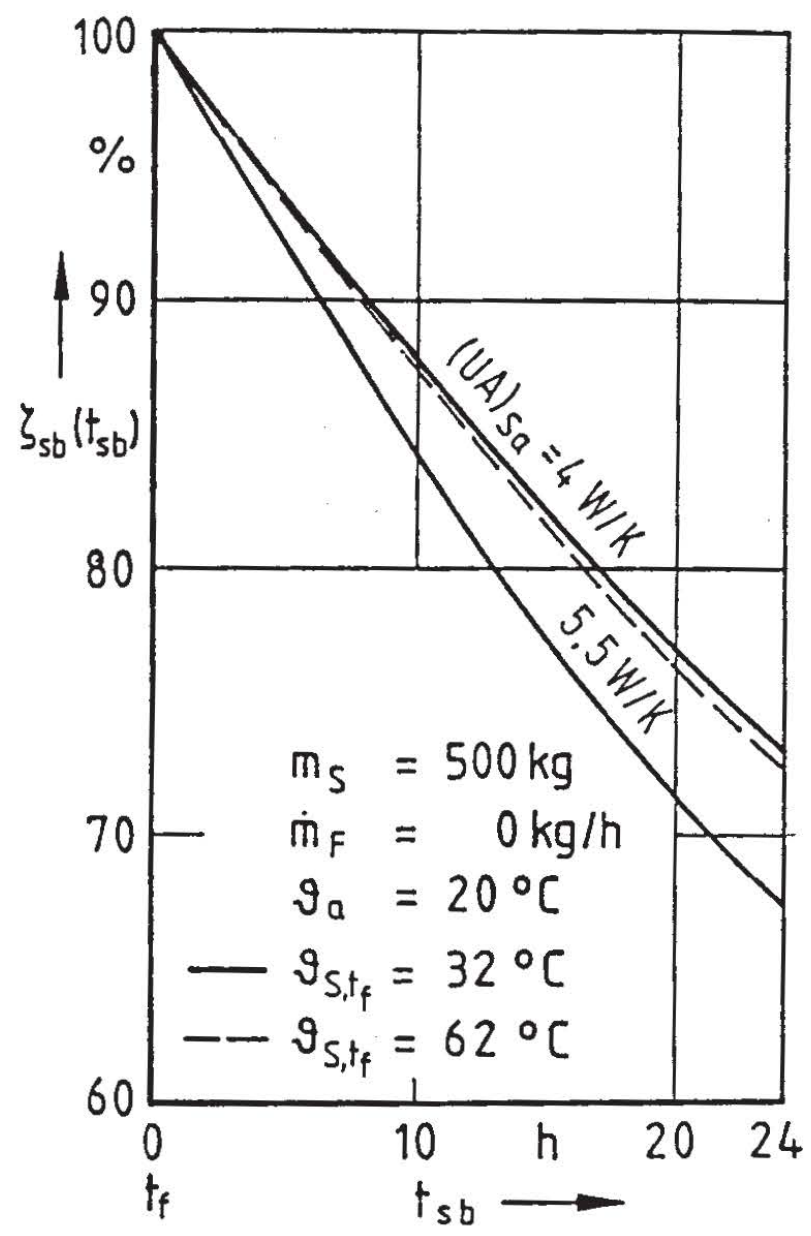

FIGURE 12 .

Exergetic standby efficiency of a charged fully mixed store vs. standby time

The exergy of the store at any time of standby is

$$
E_{x}^{s b}(T(t))=m_{S} c_{p S}\left[T_{S}(t)-T_{a}-T_{a} \ln \frac{T_{S}(t)}{T}\right]
$$

with $T_{S}(t)=\vartheta_{S}(t)+273.15$ from

$$
\vartheta_{S}(t)=\vartheta_{a}+\left(\vartheta_{S O}-\vartheta_{d}\right) \exp \left(-\frac{(U A)_{S a}}{m_{S} C_{p S}} t\right)
$$

and the exergy of the store at $t_{f}$ obtained from equ. (31)

$$
E_{x S}^{c}\left(T_{t f}\right)=\int_{0}^{t} \dot{E}_{x S}^{c}(T(t)) d t
$$

Due to the heat losses, the exergetic standby efficiency will decrease with time, as shown in FIGURE 12. The effect of the heat loss rate is obvious: the larger the heat loss rate, the steeper the decline in efficiency. The starting temperature (after charging the store) $\vartheta_{S t_{f}}$ shows only a minor 
effect. At any rate, heat losses are highly influential during standby - much more than during charging - and call for good insulation. For comparisons it is necessary to agree on a certain standby time, e.g. some manifold of the charging time.

\section{THE EXERGETIC EFFICIENCY FOR DISCHARGING}

In order to save another temperature drop in a heat exchanger, most domestic hot water stores are discharged in a displacement procedure: cold water is fed into the lower part of the store and displaces the hot water out of the upper part. Great care is taken that the incoming cold water does only little mix with the hot stored water. The assumption of a fully mixed store would, therefore, be unrealistic. It is assumed for discharge that it can be done in a piston-like flow without internal mixing.

For a cold water inflow $\dot{\mathrm{m}}_{\mathrm{Fcold}}$, there is a characteristic discharging time

$$
t_{d c}=\frac{{\sum m_{S i} c_{i}}_{m_{F c o l d} c_{c o l d}}}{\dot{m}_{F c o l d}}
$$

for the full displacement of the hot water. The discharge time may be equal to the charging time.

Full unmixed displacement of hot water yields a $100 \%$ efficiency. This value is taken here for the comparison with real stores instead of an exergetic equation. If the $100 \%$ value is not reached, the store suffers from internal mixing and external losses.

8. OVERALL EXERGETIC EFFICIENCY

The partial efficiencies for the three operation modes can be combined in an overall exergetic efficiency of the store

$$
\zeta_{\text {overall }}=\zeta_{c} \cdot \zeta_{s b} \cdot \zeta_{d c}
$$

As these efficiencies depend on time, it is suggested to use the filling time, equal to the discharge time according to equs. $(8,38)$. For the standby time, a realistic period, of course, would be best. But this realistic period may differ for different stores, an unbiased time could be 24 hours.

9. APPLICATION OF THE EXERGETIC COMPARISON

In order to find an answer to the question "how does a store handle stratification and how can this be quantified", experiments were performed with two domestic hot water stores shown in FIGURE 13. Characteristic data of the stores are given in TABLE 1 . 


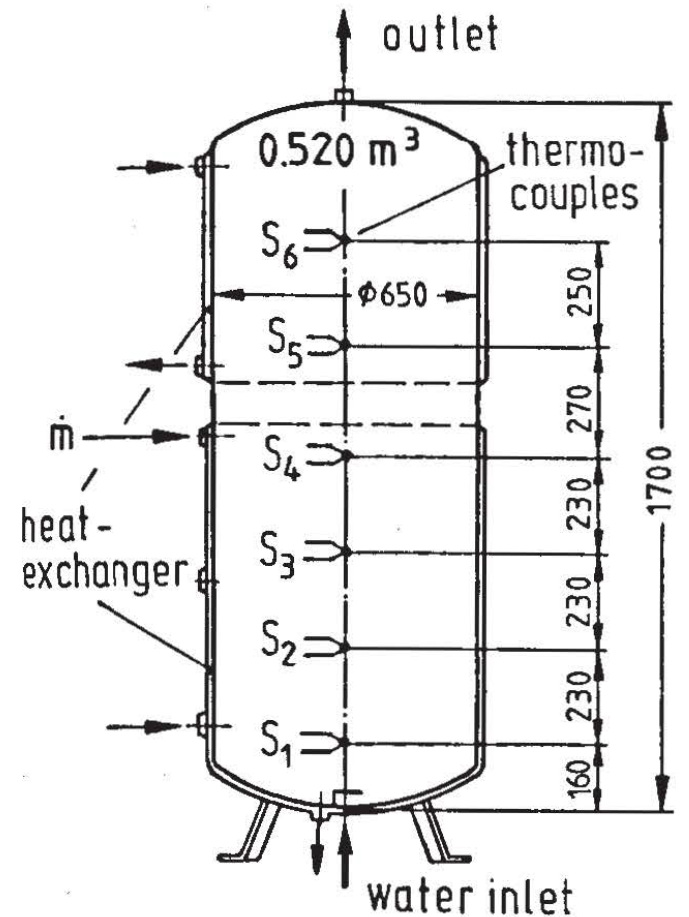

Store 1

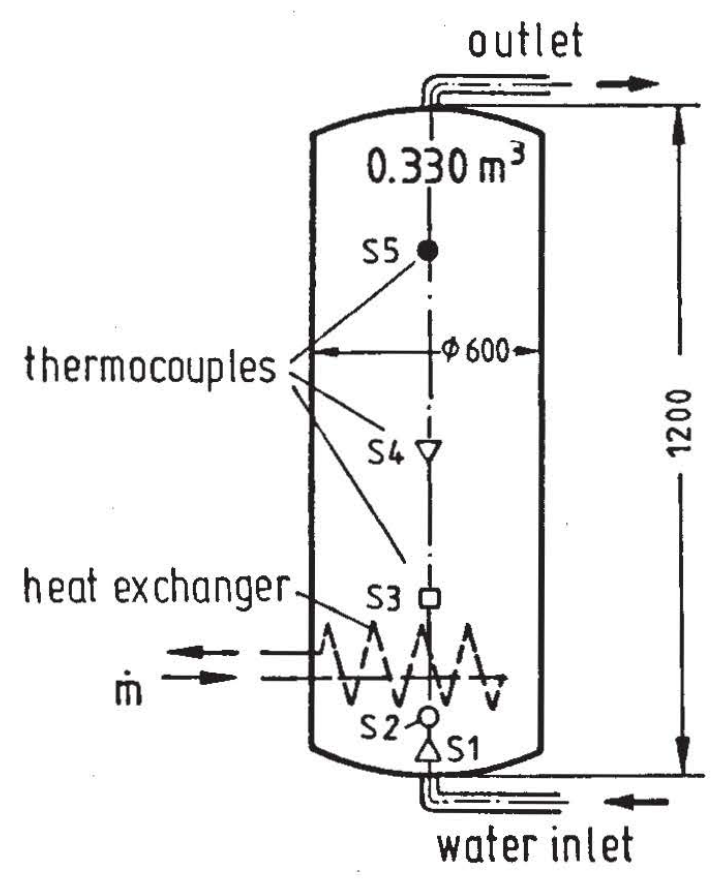

Store 2

FIGURE 13. Warmwater stores used for measurements and comparison

TABLE 1. Data of the two investigated hot water stores

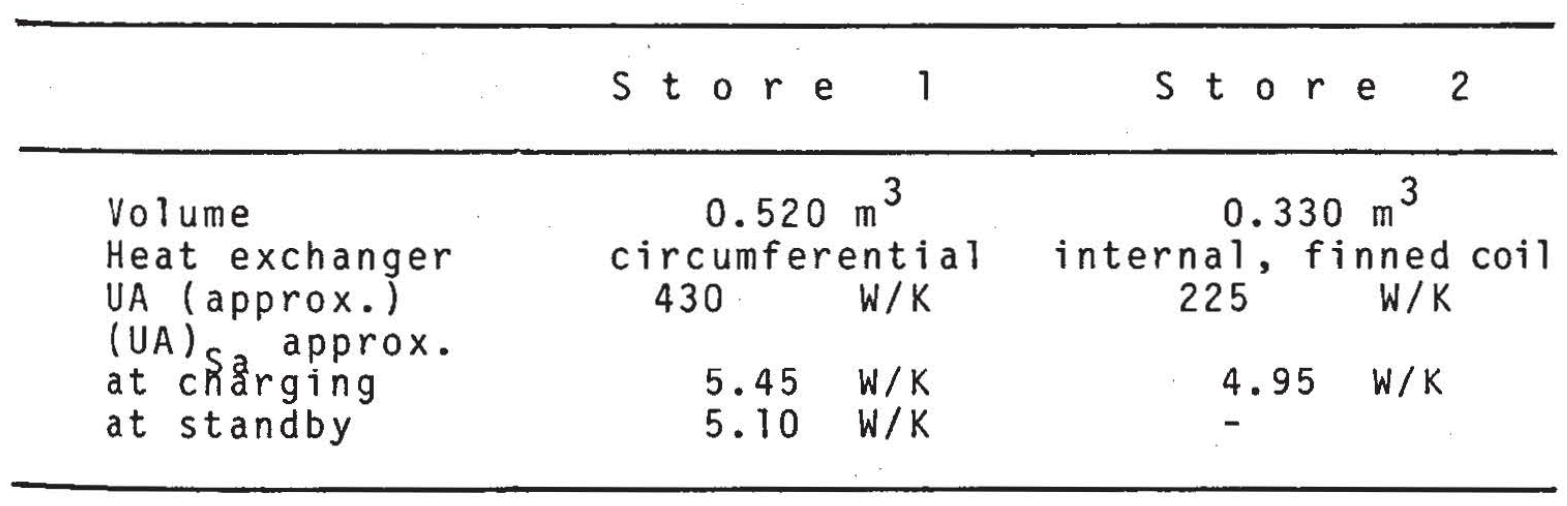

Temperatures inside the stores were measured in different heights. From these the thermal stratification and the exergy was calculated. These actual data were compared to theoretically obtained data for the fully mixed store (except for discharging where $100 \%$ efficiency was pre-assumed). The results of this comparison are presented in TABLE 2 .

For charging and standby, the experimental efficiencies are higher than the theoretical: this indicates that there actually appears a stratification in these processes. This is quite smali for charging, but pronounced for standby. 
TABLE 2. Exergetic efficiencies from experiment and theory

S t 0 re 1 s tore 2

\begin{tabular}{|c|c|c|c|c|}
\hline Efficiencies \% & $\begin{array}{l}\text { experiment } \\
\text { stratified }\end{array}$ & $\begin{array}{l}\text { theory } \\
\text { fully mixed }\end{array}$ & $\begin{array}{l}\text { experiment } \\
\text { stratified }\end{array}$ & $\begin{array}{c}\text { theory } \\
\text { fully mixed }\end{array}$ \\
\hline $\begin{array}{l}\zeta \quad \text { at }\left(t_{f}\right) \\
\zeta \text { sb at } 22 h \\
\zeta d c \text { at }\left(t_{d c} \quad t_{f}\right)\end{array}$ & $\begin{array}{l}47 \cdot 3 \\
77 \cdot 2 \\
92 \cdot 3\end{array}$ & $\begin{array}{r}46.9 \\
70.7 \\
100.0\end{array}$ & $\begin{array}{l}42.6 \\
73.9 \\
87.4\end{array}$ & $\begin{array}{r}41.9 \\
65.3 \\
100.0\end{array}$ \\
\hline$\zeta_{\text {overall }}$ & 33.7 & 33.2 & 27.5 & 27.4 \\
\hline
\end{tabular}

For discharging the experimental values do not reach the theoretical $100 \%$. This means that there is internal mixing which deteriorates the ideal piston flow. In every operationmode, store 1 appears more efficient than store 2. For the charging mode it must be said, however, that experimental conditions were not the same, so that the higher efficiency of store 1 may be - fully or in part - due to a higher temperature level. Store 1 is clearly superior for standby and discharge: since the external losses are about the same (or even somewhat larger for store 1), store 2 most likely suffers from higher internal losses, especially to the section underneath the heat exchanger which is scarcely heated during charging. More internal mixing occurs in store 2 during discharge.

A comparison according to energetic efficiencies would also bring forth that store 1 is better than store 2; it would not give, however, information on stratification.

The overall exergetic efficiency of about $30 \%$ is $10 \mathrm{w}$. An energetic efficiency would give higher numbers (e.g. for store 2 , standby $\eta \mathrm{sb}=85 \%$ instead of $\zeta_{\mathrm{sb}}=74 \%$ ), since only the energy loss, sand not the decline in temperature is accounted for. But also energetic overall efficiencies hardly exceed $50 \%$ for these stores.

The most unsatisfactory efficiencies are those for charging and standby: The low efficiency for charging is due to internal mixing: the minimum exergy of full mixing which is assumed for theoretical calculations is unfortunately, not much exceeded in reality. Ways for direct charging have to be considered and a suppression of mixing. For long standby times, the existing insulation is not satisfactory.

\section{ACKNOWLEDGMENT}

This work was performed under financial support from the German Ministry for Research and Technology; the authors gratefully acknowledge this support. 
NOMENCLATURE

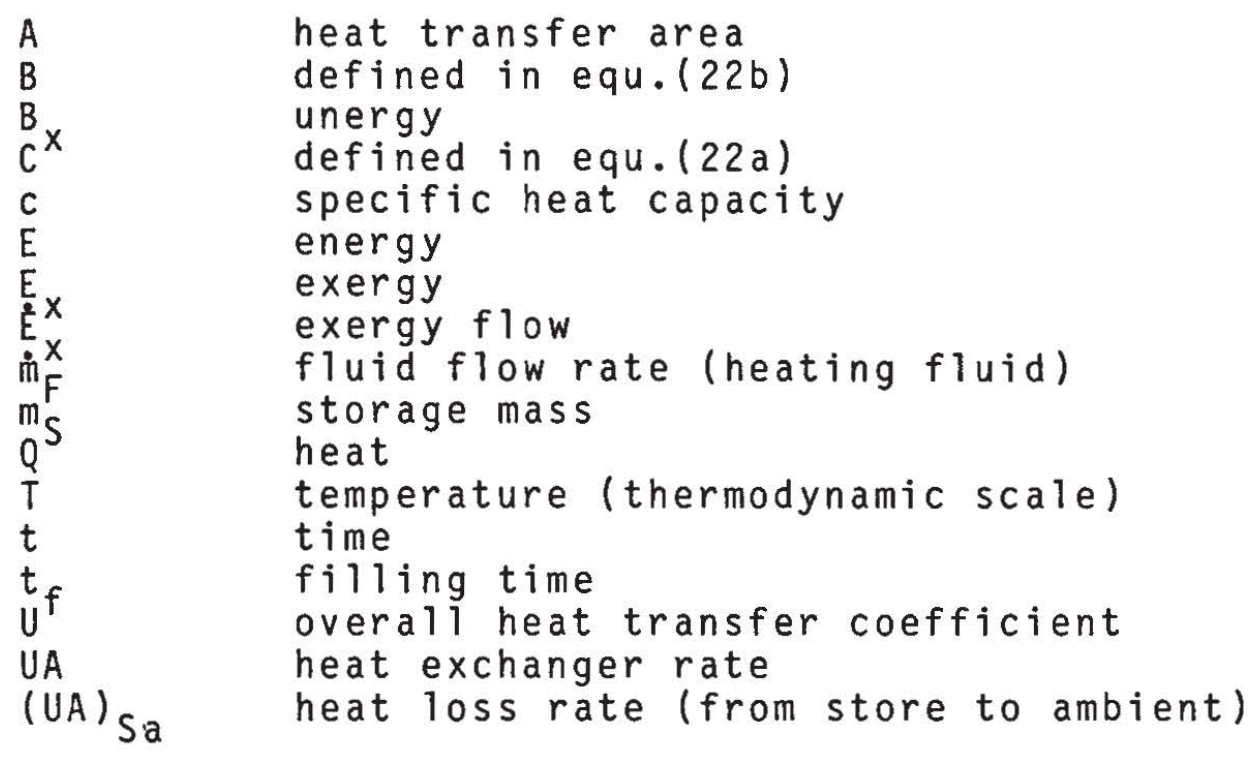

Greek symbols

$\begin{array}{ll}\Delta & \text { difference } \\ \varepsilon & \text { heat exchanger efficiency } \\ \zeta & \text { exergetic efficiency } \\ \eta & \text { energetic efficiency } \\ \Im & \text { temperature (celsius scale) }\end{array}$

Indices

$\begin{array}{ll}\text { a } & \text { ambient } \\ c & \text { charging } \\ d c & \text { discharging } \\ i & \text { in (for heating fluid) } \\ 0 & \text { initial (zero) } \\ 0 & \text { out (for heating fluid) } \\ \text { p } & \text { constant pressure } \\ \text { s } & \text { store } \\ \text { sb } & \text { standby }\end{array}$

\section{REFERENCES}

1. Gagglioli, R.A.: Second Law Analysis of a Solar Domestic Hot Water Heating System, Analysis of Energy Systems - Desing and Operation, Winter annual meeting of the A.S.M.E., Vol.1, pp.135 to 148, 1985.

2. Ahern, J.A.: The Exergy Method of Energy Systems Analysis, John Wiley and Sons, New York, 1980.

3. McKnight, R.S., et.al.: The second law analysis of a solar DHW system with low flow and stratified storage, Advances in Solar Energy Technology, Pergamon Press, Vo1.1, pp. 874 to $876,1988$. 